\title{
Spring and autumn reproduction of Calanus sinicus in the Yellow Sea
}

\author{
Shiwei Wang ${ }^{1,2}$, Chaolun Li $^{1}$, Song Sun ${ }^{1,3, *}$, Xiuren Ning ${ }^{4}$, Wuchang Zhang ${ }^{1}$ \\ ${ }^{1}$ Key Laboratory of Marine Ecology and Environmental Sciences, Institute of Oceanology, Chinese Academy of Sciences, \\ 7 Nanhai Road, Qingdao 266071, PR China \\ ${ }^{2}$ Graduate University, Chinese Academy of Sciences, 19 Yuquan Road, Beijing 100049, PR China \\ ${ }^{3}$ Jiaozhou Bay Marine Ecosystem Research Station, Chinese Ecosystem Research Network, 7 Nanhai Road, \\ Qingdao 266071, PR China
}

${ }^{4}$ Key Laboratory of Marine Biology and Biogeochemistry, Second Institute of Oceanography, State Oceanic Administration, 36 Baochu North Road, Hangzhou 310012, PR China

\begin{abstract}
The fecundity, hatching success and naupliar survival of Calanus sinicus were studied in the Yellow Sea during research cruises in April and October 2006, with emphasis on the regulation of reproduction. During both cruises, the egg production rate (EPR) showed large spatial variations ( 0 to 25.4 eggs female ${ }^{-1} \mathrm{~d}^{-1}$ ), generally coinciding with the food availability. In April, the abundant phytoplankton and ciliates in the study area supported active reproduction, which would probably initiate the annual population development. In October, females remained immature in the Yellow Sea Cold Water Mass, likely due to the unfavorable environment (poor food and low temperature). However, reproduction and recruitment were high in the neritic region, which may explain the local population recovery in late autumn. Hatching success varied markedly among stations in April (4 to $85 \%)$, whereas it was high overall in the neritic region during October $(>90 \%)$. Based on the potential recruitment rates, the spring recruitment would be more important for the annual population dynamics. Female gonad maturity, body size and lipid reserve were examined in relation to fecundity. Regression analyses suggested that the reproductive index (defined as the proportion of females with mature gonads) could be an indicator for the EPR of $C$. sinicus. Among the regulating factors, external food (ciliates and phytoplankton) seems essential for reproduction, whereas inner lipid reserve may mainly serve metabolic needs. Moreover, fecundity is positively related to body size but independent of temperature, which might exert indirect influences on reproduction.
\end{abstract}

KEY WORDS: Calanus sinicus $\cdot$ Reproduction $\cdot$ Gonad maturity $\cdot$ Food limitation $\cdot$ Yellow Sea

Resale or republication not permitted without written consent of the publisher

\section{INTRODUCTION}

The copepod Calanus sinicus may account for about $80 \%$ of the total zooplankton biomass in the Yellow Sea (Chen 1964), linking primary production to higher trophic levels (Meng 2003). Given its ecological importance, it was set as one of the target species in the China-GLOBEC program (Sun 2005). C. sinicus exhibits a unique life cycle associating with the hydrographic feature of the Yellow Sea, which is a marginal sea (average depth: $44 \mathrm{~m}$ ) of the northwest Pacific that experiences seasonal thermal stratification. The C. sinicus population starts to develop from
March to April and reaches maximal abundance by June. Then the Yellow Sea Cold Water Mass (YSCWM) gradually develops in the bottom waters of the continental shelf of the Yellow Sea, characterized by the low temperatures in the bottom waters and very high water temperature above it $(\mathrm{Su} \&$ Weng 1994). Following the hydrographic change, C. sinicus maintains its major population in the YSCWM under diapause over the summer (Pu et al. 2004), with extremely low population abundance in the nearshore region due to the unfavorable high temperature. When the stratification weakens in late autumn to winter, C. sinicus emerges from the YSCWM and 
gradually distributes itself across the Yellow Sea, thus completing the annual cycle (Sun 2005).

Several studies have reported the reproductive characteristics of Calanus sinicus in the Yellow Sea. Spring and autumn are 2 critical periods for the recruitment of C. sinicus (Zhang 2003, Sun 2005). While fecundity is low in March but high in May and June (Zhang et al. 2005), there are few data showing whether active reproduction begins in April when the spring phytoplankton bloom usually occurs and C. sinicus population starts rising in the coastal waters. It is necessary to know the connections among the food availability, reproduction and population dynamics of $C$. sinicus in early spring. On the other hand, Zhang et al. (2007) reported that reproduction of $C$. sinicus nearly ceases in the YSCWM during summer, but it remains unclear whether this continues to late autumn when the stratification weakens and C. sinicus is thought to terminate dormancy (Su \& Weng 1994, Sun 2005). In the meantime, the summer-declined population would gradually recover in nearshore areas (Wang \& Zuo 2004, Sun 2005). We are not sure whether this process is mainly driven by the local recruitment or advection from the central region where the population is larger.

Many factors can influence the in situ egg production of marine copepods (Bunker \& Hirst 2004). (1) The energy required by reproduction may come from 2 nutritional sources; the external food supply usually has primary influence on fecundity (e.g. Uye \& Murase 1997, Niehoff 2000, Runge et al. 2006), whereas the inner lipid reserve may have varying roles during reproduction of different species (Lee et al. 2006, Niehoff 2007, Jónasdóttir et al. 2008). In the Yellow Sea, Calanus sinicus can accumulate lipid in the oil sac; however, previous studies have focused on the effect of food (Uye \& Murase 1997, Zhang et al. 2005, Huo et al. 2008), leaving the role of lipid reserve during reproduction unknown. (2) Other factors such as temperature, body size, age and feeding history can also influence reproduction either directly or indirectly (Hirche et al. 1997, Rey et al. 1999, Campbell \& Head 2000, Rey-Rassat et al. 2002, Bunker \& Hirst 2004, Castellani \& Altunbaaş 2006). In the field, the effects of these factors can be complicated due to the interactions among them, which may be clarified by multivariate statistical analysis (Gislason 2005, Castellani \& Altunbaş 2006). To our knowledge, the influences of these factors on reproduction of $C$. sinicus have only been studied sporadically. (3) Knowledge on gonad development, which can give us a mechanistic understanding of copepod reproduction (Niehoff 2007), is still lacking in C. sinicus. To sum up, a comprehensive understanding of the regulation on reproduction of $C$. sinicus is required.

In this study, we conducted 2 surveys during April and October to November, measuring the fecundity, hatch- ing success and naupliar survival of Calanus sinicus to reveal the recruitment in relation to population dynamics. We focused especially on the gonad maturity of $C$. sinicus, trying to elucidate how its reproduction is regulated by a set of environmental and intrinsic factors.

\section{MATERIALS AND METHODS}

We conducted 2 cruises in the southern Yellow Sea during 10 to 30 April and 18 October to 4 November 2006. At each station, hydrography, chlorophyll a (chl a) concentration, ciliate abundance, as well as population abundance and structure were examined. Measurements of the reproductive rates and female body features were made at some selected stations (Fig. 1).

Physical and food environment. Temperature and salinity profiles were acquired by a CTD (Seabird Electronics, SBE 25). For chl a measurements, $500 \mathrm{ml}$ of seawater was collected at a series of depths $(0,5,10$, $20,30,50$, and $70 \mathrm{~m}$, depending on the water depth) and GF/F filtered. Samples were then stored at $-20^{\circ} \mathrm{C}$ in the dark for $2 \mathrm{~d}$ before pigment extraction in $90 \%$ acetone for $24 \mathrm{~h}$. The chl a concentration was measured with a Turner Designs fluorometer. The mean chl a concentration was calculated by dividing the integrated values throughout the whole water column at stations in April and the neritic stations in October. At stations inside the YSCWM in October, given that Calanus sinicus inhabits waters beneath the thermocline to avoid high temperature (Wang \& Zuo 2004), we calculated the mean chl $a$ of the respective layers rather than the whole water column.

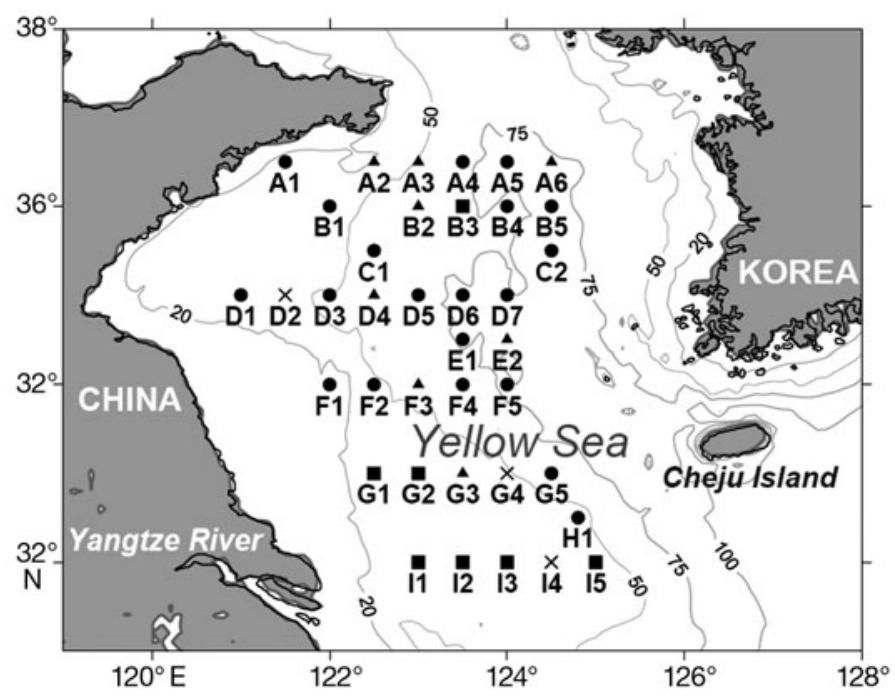

Fig. 1. Study area. Stations with egg production measurements in both cruises (๑), only in April (ם), only in October $(\boldsymbol{\Delta})$ and stations without egg production measurement $(X)$ are shown. Contour lines indicate isobaths (m) 
At the same layers of the chl a samples, 11 ciliate samples were collected and preserved with $1 \%$ acid Lugol's iodine solution in plastic bottles. The total abundance of ciliates was examined under an Olympus CKX41 inverted microscope at $100 \times$ magnification after pre-concentration by serial settling methods. We calculated the mean ciliate abundance following the same method for chl a.

Sampling and egg production experiment. To determine the population abundance and structure, copepods were collected by a $500 \mu \mathrm{m}$ mesh zooplankton net (mouth opening $0.5 \mathrm{~m}^{2}$ ) and preserved in $5 \%$ formalin seawater solution. All tows were carried out vertically from $4 \mathrm{~m}$ above the bottom to the sea surface. Calanus sinicus was enumerated by developmental stages back in the laboratory. Our plankton net was too coarse for quantitatively collecting $\mathrm{C} 1$ to $\mathrm{C} 3$ (body width: $<\sim 480 \mu \mathrm{m}$; without the appendages), so we only present the abundance of the later stages ( $\mathrm{C} 4$ to $\mathrm{C} 6$ : body width > 600 $\mu \mathrm{m})$.

For egg production rate (EPR) measurements, additional vertical hauls were taken to catch live females. After capture, samples were immediately diluted into a 201 bucket filled with in situ seawater. Then 25 to 50 healthy females of Calanus sinicus were sorted with a wide-mouthed pipette into either plastic cylinders (volume: $350 \mathrm{ml}$; with false bottom of $330 \mu \mathrm{m}$ mesh size to prevent cannibalism; 5 females per cylinder) or 6 well tissue culture plates (12 ml each well; 1 female per well). We added $70 \mu \mathrm{m}$ filtered in situ seawater as the culture water. All cultures were placed under ambient temperature. For the bottle culture, eggs were collected and counted after $24 \mathrm{~h}$, whereas for the multiwell incubation, to minimize the influence of cannibalism, eggs were checked every 4 to $6 \mathrm{~h}$ and removed after counting during the $24 \mathrm{~h}$ incubation period. We found no significant difference of the EPR values between the 2 incubation methods in 20 parallel experiments (Wilcoxon signed ranks test, $\mathrm{p}>0.1$ ), similar to Niehoff et al. (1999). We found that cannibalism was negligible in both methods.

For hatching success (HS) measurements, at each station more than 80 eggs (originated from at least 12 females) were gently transferred by a pipette into petri dishes filled with $0.45 \mu \mathrm{m}$ filtered seawater under ambient temperature. Hatched nauplii were counted every $12 \mathrm{~h}$ until hatching was complete. In October, we also measured naupliar survival (NS) by incubating the nauplii until Stage N3. HS was calculated as the proportion of nauplii to the total eggs at the start of the incubation, whereas NS was calculated as the proportion of the final N3s to the initial eggs.

Female body features. At each station with egg production experiments, prosome length (PL), gonad development and oil sac volume of more than 30 (usu- ally >40) females were examined under a dissecting microscope using formalin-preserved samples. Gonad development stages were determined following the procedures of Niehoff \& Runge (2003). Four stages were classified: GS1, GS2 and GS3 were defined as immature females with increasing maturity, while GS4 represented mature females ready to spawn. The reproductive index (RI) was defined as the proportion of GS4 females. Measured laterally, oil sac volume (OSV) was calculated by the following equation: $\mathrm{OSV}=(1 / 6) \pi \mathrm{L} \mathrm{W} \mathrm{W}^{2}$ (Svetlichny et al. 2006), where $\mathrm{L}$ and $\mathrm{W}$ are the length and maximal width of oil sac, respectively.

Statistical analysis. All statistical analyses were performed using SPSS software (v.13.0). Mann-Whitney $U$-tests were used to compare the regional and seasonal differences. Normality and homogeneity were examined by applying Kolmogorov-Smirnov and Bartlett tests, respectively. Before regression analyses, the EPR data was log $(E P R+1)$ transformed for normalization. Given the vertical mixing of the water column in April and the near-bottom distribution pattern of Calanus sinicus in October (Wang \& Zuo 2004), bottom temperature was adopted to represent the habitat temperature. To examine the relationships between fecundity and either external factors (temperature, chl a concentration and ciliate abundance) or internal factors (PL, RI and OSV), we performed both univariate regressions (simple linear regressions and non-linear regressions when necessary) and multiple stepwise linear regressions.

\section{RESULTS}

\section{Physical and food environment}

In April, both bottom and surface temperature gradually increased southward, ranging from $4.9^{\circ} \mathrm{C}$ to $13.4^{\circ} \mathrm{C}$ (Fig. 2A,B). The water column was well mixed over the study area (Fig. 2C). The mean chl a concentration and ciliate abundance were generally higher in the north of transact $E$ than in the south (MannWhitney $U$-tests, $\mathrm{p}<0.01$ in both parameters). In the northeast, a diatom bloom (mostly Thalassiosira pacifica) had developed, with surface chl a reaching to a maximum of $15 \mathrm{mg} \mathrm{m}^{-3}$ at Stn B5. In most parts of the southern region, chl a was relatively low (mostly $<0.8 \mathrm{mg} \mathrm{m}^{-3}$ ), particularly in the southeast (Fig. 2D). The ciliate abundance was also lowest in the southeast but peaked in the northwest (Fig. 2E).

In October, the YSCWM dominated the central part of the survey region (Fig. 3). According to Weng \& Wang (1982), we adopted the $10^{\circ} \mathrm{C}$ bottom isotherm as the boundary of the YSCWM, which was characterized by 

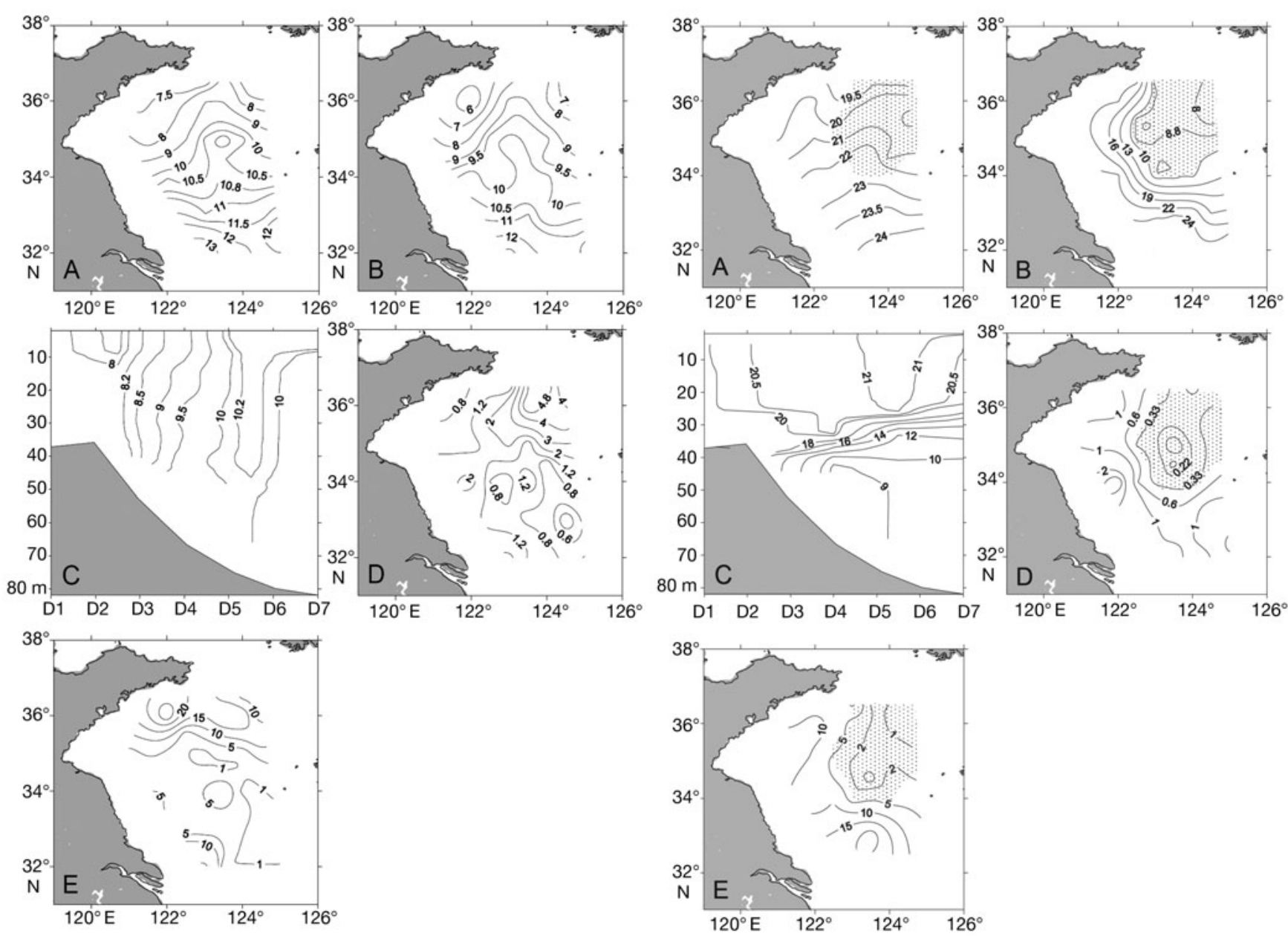

Fig. 2. Distribution of (A) surface temperature $\left({ }^{\circ} \mathrm{C}\right)$, (B) bottom temperature $\left({ }^{\circ} \mathrm{C}\right)$, (D) mean chl a concentration $\left(\mathrm{mg} \mathrm{m}^{-3}\right)$ and (E) mean ciliate abundance $\left(10^{2}\right.$ ind. $\left.\mathrm{l}^{-1}\right)$ in April 2006. The vertical temperature profile along Transect $\mathrm{D}\left(35^{\circ} \mathrm{N}\right.$; see Fig.1) is shown in (C), with the $x$-axis indicating stations and the $y$-axis representing water depths $(\mathrm{m})$

thermal stratification (Fig. 3C), poor food conditions (chl $a<0.3 \mathrm{mg} \mathrm{m}^{-3}$, Fig. 3D; ciliate abundance $<500$ ind. $\mathrm{l}^{-1}$, Fig. 3E), and relatively high salinity ( $>33$; data not shown). By contrast, waters outside the YSCWM exhibited mixing or less stratified feature, together with lower salinity and better food supply (Fig. 3D,E).

\section{Population abundance and structure}

The abundance and structure of the later stage Calanus sinicus are shown in Fig. 4. In April, the population had a relatively homogeneous distribution over the survey region, peaking at neritic Stn D2, reaching $6.6 \times 10^{4}$ ind. $\mathrm{m}^{-2}$ (Fig. 4A). In October, except at Stn A1, the population abundance was rather low in

Fig. 3. Distribution of (A) surface temperature $\left({ }^{\circ} \mathrm{C}\right)$, (B) bottom temperature $\left({ }^{\circ} \mathrm{C}\right)$, (D) mean chl a concentration $\left(\mathrm{mg} \mathrm{m}^{-3}\right)$ and (E) mean ciliate abundance $\left(10^{2}\right.$ ind. $\left.\mathrm{l}^{-1}\right)$ in October 2006 . The vertical temperature profile along Transect $\mathrm{D}\left(35^{\circ} \mathrm{N}\right.$; see Fig.1) is shown in (C), with the $x$-axis indicating stations and the $y$-axis representing water depths $(\mathrm{m})$. The shaded areas in (A), (B), (D) and (E) indicate the territory of the Yellow Sea Cold Water Mass

the neritic region (mean 569 ind. $\mathrm{m}^{-2}$ ), compared with that in the domain of the YSCWM (mean 7671 ind. $\mathrm{m}^{-2}$; Fig. 4B). The copepodite Stage V (C5) dominated the population inside the YSCWM (mostly 50 to $80 \%$ ), whereas the neritic population mainly consisted of females (usually $>50 \%$ ).

\section{Female body features}

In April, female body size (PL) generally decreased southward, with a wide range (2.30 to $2.72 \mathrm{~mm}$; Table 1). In October, females developed a significantly smaller body with relatively narrow variation (2.08 to $2.27 \mathrm{~mm}$; Table 1) and there was no significant difference of PL between females inside and outside the 

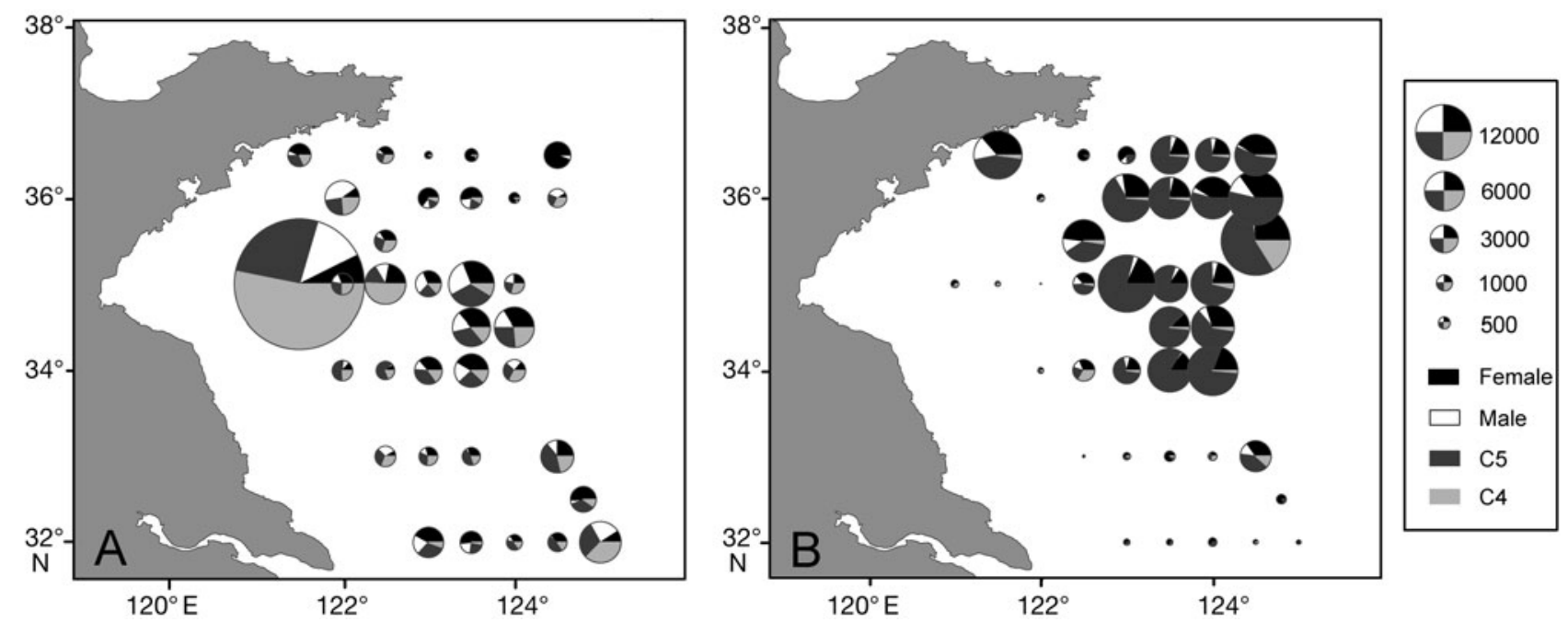

Fig. 4. Calanus sinicus. Population abundance (ind. $\mathrm{m}^{-2}$ ) and structure in (A) April and (B) October 2006. Shading in pies indicates different development stages and sex, and proportions are shown as the percentage of the pie area. Pie size: abundance (ind. $\mathrm{m}^{-2}$ ); population abundance increases linearly with the pie area at each station

YSCWM (Mann-Whitney U-test, p > 0.1). A negative relationship between PL and temperature was found (simple regression, $\mathrm{r}^{2}=0.17, \mathrm{p}<0.05$ ), in agreement with Uye (1988).

In April, most females from north of Stns E1 and E2 were mature (RI $>80 \%$ ), whereas less than $50 \%$ females were mature in most areas south of Stns E1 and E2 (Table 1). In October, females remained immature inside the YSCWM except at Stn B5 where the RI was only $5 \%$. In contrast, except for Stn A1, mature females could be found at all stations outside the YSCWM, although the RI varied greatly (9 to $90 \%$; Table 1). Combining the data from the 2 cruises, there were significant relationships between the RI and food availabilities (chl a: logarithmic regression, $\mathrm{r}^{2}=0.54, \mathrm{p}$ $<0.001$; ciliates: linear regression, $\mathrm{r}^{2}=0.16$, $\mathrm{p}<0.05$ ).

In April, lipid storage volume (represented by OSV) was higher north of Stns E1 and E2 than in the south (Mann-Whitney $U$-test, p $<0.01$; Table 1 ), probably a result of the body size difference. In October, there was no significant difference of OSV between females inside and outside the YSCWM (Mann-Whitney $U$ test, $\mathrm{p}>0.1$; Table 1). Females collected in spring generally accumulated greater amount of lipids than the ones collected in autumn (Mann-Whitney $U$-test, p < 0.001).

\section{Egg production}

During both cruises, the EPR displayed large spatial variations (April: 0 to 25.4 eggs female ${ }^{-1} \mathrm{~d}^{-1}$; October: 0 to 21.5 eggs female ${ }^{-1} \mathrm{~d}^{-1}$ ). In April, the EPR was gener- ally higher north of Stns E1 and E2 than in the south (Mann-Whitney $U$-test, $\mathrm{p}<0.01)$ and they were extremely low $\left(<1\right.$ eggs female ${ }^{-1} \mathrm{~d}^{-1}$; Fig. 5A) in the southeast. This pattern was generally coincident with the food availability, with the exception of the bloom area, where fecundities were only moderate (2.7 to 13.8 eggs female ${ }^{-1} \mathrm{~d}^{-1}$ ). In October, females spawned actively in the neritic region with an average EPR of 9.8 eggs female ${ }^{-1} \mathrm{~d}^{-1}$, whereas there was no egg production inside the YSCWM (Fig. 5B). Over the survey region, fecundities were generally higher in April than in October (Mann-Whitney $U$-test, p < 0.05).

Combining the data from both cruises, we performed the simple regression analyses (Table 2 ). The relationship between EPR and RI was very close, and it remained true when examined separately in each cruise, particularly in October (simple regression, $\mathrm{r}^{2}=0.70, \mathrm{p}<$ 0.001). Following RI, the food items (ciliate abundance and chl a concentration) showed significant and positive effects on fecundity. EPR was positively related to $\mathrm{PL}$, whereas it was independent of either temperature or OSV (Table 2). To remove the body-size effect, we calculated the relative OSV by dividing OSV by $\mathrm{PL}^{3}$. The relationship between the EPR and the relative OSV remained insignificant (simple regression, $\mathrm{r}^{2}=$ $0.10, \mathrm{p}>0.05)$.

To clarify the effects of the environmental and intrinsic variables, we performed stepwise multiple linear regressions, without incorporating the parameter 'RI'. Two models were established (Table 3). Food items showed primary importance in reproduction. In Model 1, only ciliate abundance was included, explaining $37 \%$ of the variance of $\log (\mathrm{EPR}+1)$. Chl $a$ 
Table 1. Calanus sinicus. Female body features: prosome length ( $\mathrm{PL}_{;} \mathrm{mm}$, mean $\pm \mathrm{SD}$ ), reproductive index (RI, proportion of females with mature gonad) and oil sac volume $\left(\mathrm{OSV}_{;} 10^{-2} \mathrm{~mm}^{3}\right.$, mean $\left.\pm \mathrm{SE}\right)$. ' - ' indicates no data is available. Data from stations in the YSCWM in October are in bold

\begin{tabular}{|c|c|c|c|c|c|c|}
\hline \multirow[t]{2}{*}{ Stn } & \multicolumn{2}{|c|}{$-\mathrm{PL}(\mathrm{mm})-$} & \multicolumn{2}{|c|}{ RI (\%) } & \multicolumn{2}{|c|}{$-\operatorname{OSV}\left(10^{-2} \mathrm{~mm}^{3}\right)$} \\
\hline & Apr & Oct & Apr & Oct & Apr & Oct \\
\hline A1 & $2.72 \pm 0.12$ & $2.09 \pm 0.07$ & 86 & 0 & $2.41 \pm 0.33$ & 0.00 \\
\hline A2 & - & $2.10 \pm 0.09$ & - & 10 & - & $0.03 \pm 0.02$ \\
\hline A3 & - & $2.24 \pm 0.09$ & - & 76 & - & 0.00 \\
\hline A4 & $2.33 \pm 0.16$ & $2.16 \pm 0.09$ & 97 & $\mathbf{0}$ & 0.00 & $1.53 \pm 0.25$ \\
\hline A5 & - & $2.20 \pm 0.17$ & - & $\mathbf{0}$ & - & $0.68 \pm 0.18$ \\
\hline A6 & - & $2.25 \pm 0.11$ & - & $\mathbf{0}$ & - & $1.07 \pm 0.22$ \\
\hline B1 & $2.59 \pm 0.15$ & $2.10 \pm 0.08$ & 97 & 34 & $0.76 \pm 0.25$ & $0.01 \pm 0.01$ \\
\hline B2 & - & $2.22 \pm 0.14$ & - & $\mathbf{0}$ & - & $0.92 \pm 0.21$ \\
\hline B3 & $2.43 \pm 0.23$ & - & 88 & - & $1.04 \pm 0.53$ & - \\
\hline B4 & $2.32 \pm 0.11$ & $2.20 \pm 0.14$ & 91 & $\mathbf{0}$ & $0.60 \pm 0.46$ & $0.32 \pm 0.13$ \\
\hline B5 & $2.37 \pm 0.17$ & $2.23 \pm 0.09$ & 97 & 5 & $0.45 \pm 0.33$ & $0.55 \pm 0.13$ \\
\hline $\mathrm{C} 1$ & $2.58 \pm 0.18$ & $2.22 \pm 0.09$ & 91 & $\mathbf{0}$ & $1.28 \pm 0.24$ & $0.60 \pm 0.16$ \\
\hline $\mathrm{C} 2$ & $2.52 \pm 0.24$ & - & 75 & - & $0.46 \pm 0.16$ & 0.00 \\
\hline D1 & $2.52 \pm 0.16$ & $2.08 \pm 0.06$ & 50 & 90 & $0.90 \pm 0.21$ & $0.06 \pm 0.05$ \\
\hline D3 & $2.56 \pm 0.23$ & - & 91 & - & $2.15 \pm 0.59$ & 0.00 \\
\hline D4 & - & $2.22 \pm 0.16$ & - & 28 & - & $0.35 \pm 0.09$ \\
\hline D5 & $2.52 \pm 0.11$ & $2.15 \pm 0.13$ & 86 & $\mathbf{0}$ & $0.47 \pm 0.18$ & $0.29 \pm 0.11$ \\
\hline D6 & $2.56 \pm 0.11$ & $2.21 \pm 0.15$ & 79 & $\mathbf{0}$ & $0.81 \pm 0.30$ & $0.16 \pm 0.07$ \\
\hline D7 & $2.52 \pm 0.2$ & $2.23 \pm 0.12$ & 56 & 0 & $1.39 \pm 0.35$ & $0.17 \pm 0.05$ \\
\hline E1 & $2.57 \pm 0.13$ & $2.19 \pm 0.12$ & 67 & $\mathbf{0}$ & $0.46 \pm 0.14$ & $0.15 \pm 0.12$ \\
\hline E2 & - & $2.14 \pm 0.12$ & - & 0 & - & $0.11 \pm 0.11$ \\
\hline $\mathrm{F} 1$ & $2.62 \pm 0.15$ & $2.19 \pm 0.10$ & 66 & 67 & $1.39 \pm 0.34$ & $0.79 \pm 0.39$ \\
\hline $\mathrm{F} 2$ & $2.59 \pm 0.17$ & $2.27 \pm 0.07$ & 19 & 82 & $3.33 \pm 0.61$ & $1.46 \pm 0.25$ \\
\hline F3 & - & $2.18 \pm 0.13$ & - & $\mathbf{0}$ & - & $0.40 \pm 0.14$ \\
\hline F4 & $2.41 \pm 0.11$ & $2.20 \pm 0.11$ & 94 & $\mathbf{0}$ & $0.14 \pm 0.12$ & $0.29 \pm 0.15$ \\
\hline F5 & $2.33 \pm 0.08$ & $2.21 \pm 0.11$ & 81 & $\mathbf{0}$ & $0.03 \pm 0.03$ & $0.06 \pm 0.04$ \\
\hline G1 & $2.45 \pm 0.22$ & - & 43 & - & $0.22 \pm 0.22$ & - \\
\hline $\mathrm{G} 2$ & $2.32 \pm 0.16$ & - & 46 & - & 0.00 & - \\
\hline G3 & - & $2.26 \pm 0.13$ & - & 10 & - & $0.89 \pm 0.27$ \\
\hline G5 & $2.30 \pm 0.14$ & $2.26 \pm 0.08$ & 22 & 36 & 0.00 & $2.18 \pm 0.29$ \\
\hline H1 & $2.35 \pm 0.09$ & $2.21 \pm 0.08$ & 26 & 9 & 0.00 & $1.01 \pm 0.29$ \\
\hline I1 & $2.37 \pm 0.13$ & - & 59 & - & $0.45 \pm 0.18$ & - \\
\hline I2 & $2.32 \pm 0.09$ & - & 27 & - & $0.03 \pm 0.01$ & - \\
\hline I3 & $2.32 \pm 0.10$ & - & 39 & - & 0.00 & - \\
\hline I5 & $2.36 \pm 0.12$ & - & 31 & - & $0.19 \pm 0.13$ & - \\
\hline Average & 2.46 & 2.19 & 65 & 17 & 0.73 & 0.50 \\
\hline Range & $2.30-2.72$ & $2.08-2.27$ & $19-97$ & $0-90$ & $0-3.33$ & $0-2.18$ \\
\hline
\end{tabular}

concentration was added into Model 2, which explained $45 \%$ of the variability.

\section{Hatching success and naupliar survival}

The HS varied largely over the survey region in April (4 to $85 \%$; Fig. 5C). In October, however, most eggs hatched successfully (90 to 100\%; Fig. 5D) and survived to N3 (NS > 85\%; data not shown) in the neritic region, where reproduction was active. There was no significant relationship between HS and any of the environmental or internal factors measured in the present study.

\section{DISCUSSION}

\section{Reproduction and recruitment}

The magnitudes of egg production in April were comparable to the high fecundities in late spring (Zhang 2003), indicating active reproduction began then, which agrees with Chen (1964), who inferred the same result from population data. The food supply in the northern part of the study area initiated the active reproduction, which may further explain the population increase in early spring observed by Sun (2005). Although fecundity generally coincided with food conditions, the EPR was only moderate in the diatom bloom area, where ciliate was also relatively abundant (Fig. 5A). The population there seemed to be entering the active reproducing phase, judging by the high proportion of mature females (Table 1). In this case, it is likely that fecundity was limited by nutritional deficiency due to the dominance of mono diatom species (Pond et al. 1996, Jónasdóttir et al. 2002), as laboratory experiments have demonstrated that mixed diets could sustain higher EPR than some single diatom diets in Calanus sinicus (Li et al. 2006).

During the autumn cruise, the population features (population aggregation and C5 dominance) and the inactive reproduction of Calanus sinicus in the YSCWM were similar to conditions in summer (Wang et al. 2003, Li et al 2004, Zhang et al. 2007), suggesting the impact of the thermal stratification would at least continue to early November. This confirms that the YSCWM provides a shelter for $C$. sinicus to survive rather than stimulating reproduction (Wang \& Zuo 2004, Zhang et al. 2007). On the other hand, fecundities outside the YSCWM were higher than those in summer (Zhang 2003), probably a response to the more favorable food and temperature conditions (Fig. 3). Compared with the unsuccessful summer recruitment (Zhang et al. 2007), the relatively high EPR, HS and NS in the nearshore area implied the high potential of population increase, which could also be confirmed by the high proportion of $\mathrm{N} 1$ to $\mathrm{C} 3$ (> 80\% of total abundance) collected by a finer zooplankton net (Huo et al. 2008). We infer that the recovery of the nearshore population in late autumn (Wang \& Zuo 2004, Sun 2005) 

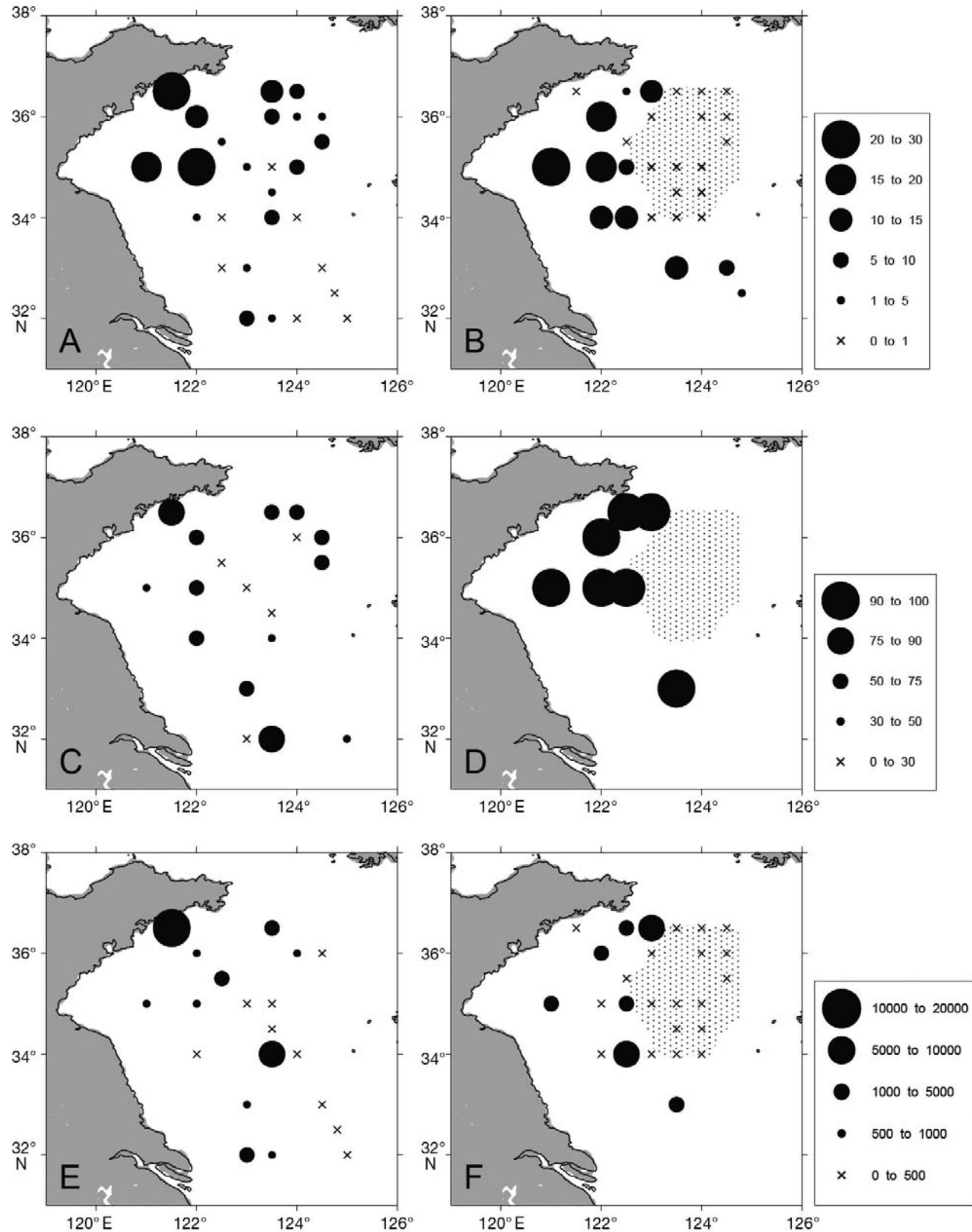

Fig. 5. Calanus sinicus. (A,B) Egg production rate (eggs female $\left.{ }^{-1} d^{-1}\right),(C, D)$ egg hatching success $(\%)$ and $(E, F)$ potential recruitment rate $\left(P R R\right.$, nauplii $\mathrm{m}^{-2} \mathrm{~d}^{-1}$ ) during April and October 2006, respectively. Shaded areas in B, D and F indicate Yellow Sea Cold Water Mass 
Table 2. Calanus sinicus. Regressions of log-transformed egg production rate $(E P R+1)$ versus RI (reproductive index, proportion of females with mature gonad), mean ciliate abundance (ind. $\left.\mathrm{l}^{-1}\right)$, chl a concentration $\left(\mathrm{mg} \mathrm{m}^{-3}\right)$, body size (prosome length $[\mathrm{PL}], \mathrm{mm})$, temperature $\left({ }^{\circ} \mathrm{C}\right)$ and oil sac volume $\left(10^{-2} \mathrm{~mm}^{3}\right)$. See 'Materials and methods' for more details. Sample sizes (n), adjusted $\mathrm{R}^{2}$, and significance levels $(\mathrm{p})$ are given. Regressions with $\mathrm{p}<0.05$ are marked by ${ }^{*}$

\begin{tabular}{|llllll|}
\hline Variable & \multicolumn{1}{c}{ Regression } & $\mathrm{n}$ & $\begin{array}{c}\text { Ajusted } \\
\mathrm{R}^{2}\end{array}$ & $\mathrm{p}$ \\
\hline $\mathrm{RI}(\%)$ & $\log (\mathrm{EPR}+1)=0.009 \mathrm{RI}+0.098$ & 51 & 0.50 & $<0.001^{*}$ \\
Ciliates & $\log (\mathrm{EPR}+1)=0.266 \ln ($ ciliates $)-1.038$ & 48 & 0.40 & $<0.001^{*}$ \\
Chl $a$ & $\log (\mathrm{EPR}+1)=0.233 \ln (\mathrm{chl} a)+0.541$ & 50 & 0.25 & $<0.001^{*}$ \\
Body size & $\log (\mathrm{EPR}+1)=0.988 \mathrm{PL}-1.808$ & 51 & 0.11 & $0.019^{*}$ \\
Temperature & $\log (\mathrm{EPR}+1)=0.028 \mathrm{~T}+0.188$ & 53 & 0.04 & 0.071 \\
Oil sac & $\log (\mathrm{EPR}+1)=16.817$ OSV +0.382 & 51 & 0.04 & 0.083 \\
volume & & & & & \\
\hline
\end{tabular}

may be driven by local recruitment rather than advection from the population abundant area (the YSCWM), where individuals under Stage C4 were rare.

In contrast to Zhang et al. (2005), who recorded high HS in Calanus sinicus, we found that HS in April varied largely (4 to $85 \%$; Fig. 5C), but it was not related to any of the environmental or internal parameters measured in the present study. At first, we found that most non-hatched eggs had undergone cleavages of different levels and some had even developed embryonic forms in the membranes. These findings, together with the relatively high proportions of males, indicate that the hatching failures were not due to the eggs' being unfertilized. Furthermore, we barely observed female senescence, which may also lower the egg viability (Pond et al. 1996, Jónasdóttir et al. 2002 and references therein), suggesting senescence can not explain the low HS either. Moreover, many authors have reported the inhibition of some diatom species on copepod egg viability (Poulet et al. 1994, Miralto et al. 1999, Jónasdóttir et al. 2002, Halsband-Lenk et al. 2005). However, HS does not seem to be related to the diatom concentration; it was generally moderate (50 to $75 \%$; Fig. $5 \mathrm{C}$ ) in the diatom bloom area, in contrast to the central region, where diatom concentration was much lower and HS was lowest (Figs. 3D \& 5C), increasing the complication of this issue.
We estimated the potential recruitment rate (PRR) of the Calanus sinicus population at each station by the following equation: PRR (nauplii $\mathrm{m}^{-2} \mathrm{~d}^{-1}$ ) $=$ female abundance (ind. $\mathrm{m}^{-2}$ ) $\times \mathrm{EPR}$ (eggs female $\left.\mathrm{d}^{-1}\right) \times \mathrm{HS}(\%)$. In April, the recruitment could occur across most of the study area with varying rates, whereas it was restricted to the nearshore region in October (Fig. 5E,F). Over the whole survey region, the PRR in April was higher than that in October (Mann-Whitney $U$-test, $\mathrm{p}<0.05$; with average values of 1848 and 1118 nauplii $\mathrm{m}^{-2} \mathrm{~d}^{-1}$, respectively), suggesting the spring recruitment might be more important for the annual population dynamics. This assertion is further supported when we take into account the fact that reproduction of $C$. sinicus is longer and of greater magnitude in spring than in autumn (Zhang 2003, this study).

\section{Gonad maturity}

Among all the examined parameters, RI was most closely related to the fecundity of Calanus sinicus (Table 2), agreeing with previous findings in other copepod species (e.g. Campbell \& Head 2000, Ceballos et al. 2004, Ceballos \& Álvarez-Marqués 2006). This indicates that the reproductive intensity of $C$. sinicus is generally dependent on the population maturity over temporal and spatial ranges in the Yellow Sea. This relationship also enables us to estimate in situ EPR by formalin-preserved samples in the future (Niehoff \& Runge 2003). In addition, the close relationships between RI and food availability suggest external food may be essential for gonad maturation.

Food limitation may be one possible explanation for female immaturity: most females remained at Stage GS1 or GS2 inside the YSCWM (Table 1). In Calanus species, the development of immature stages (GS1 to GS3) can be fueled by body reserves (Hirche 1996, Niehoff \& Hirche 1996), whereas the final matu-

Table 3. Calanus sinicus. Results of stepwise multiple linear regressions with log-transformed egg production rate (EPR +1 ) as the dependent variable, and ln-transformed ciliate abundance (ind. $\mathrm{l}^{-1}$ ) (ciliates), ln chl a concentration $\left(\mathrm{mg} \mathrm{m}^{-3}\right)$, prosome length $(\mathrm{PL}, \mathrm{mm})$, temperature $\left({ }^{\circ} \mathrm{C}\right)$ and oil sac volume $\left(10^{-2} \mathrm{~mm}^{3}\right)$ as the independent variables. Two models are established: (1) Only ciliate is included, and (2) ciliate and chl $a$ are included. Sample size (n), standardized partial coefficient (Beta), significance level (p) as well as the adjusted $\mathrm{R}^{2}$ are given

\begin{tabular}{|c|c|c|c|c|}
\hline \multirow{2}{*}{ Model } & \multirow{2}{*}{$\mathrm{n}$} & \multicolumn{2}{|c|}{- Beta $(p)-$} & \multirow{2}{*}{ Ajusted $\mathrm{R}^{2}$} \\
\hline & & Ciliates & Chl a & \\
\hline (1) $\log (E P R+1)=-0.995+0.256 \ln$ (ciliates) & 46 & $0.621(<0.001)$ & & 0.37 \\
\hline (2) $\log (\mathrm{EPR}+1)=-0.734+0.217 \ln ($ ciliates $)+0.143 \ln (\mathrm{chl} a)$ & 46 & $0.525(<0.001)$ & $0.316(0.008)$ & 0.45 \\
\hline
\end{tabular}


ration to GS4 usually depends on ingested food (Plourde \& Runge 1993, Hirche 1996, Niehoff 2000, Niehoff 2007). Poor food conditions are common in the YSCWM (Fig. 3D,E; Li et al. 2004, Pu et al. 2004, Zhang et al. 2007). In response, female feeding rates were extremely low there $\left(<1 \%\right.$ body carbon $\mathrm{d}^{-1}$; Huo et al. 2008), which could barely meet the metabolic requirements of C. sinicus females (Li et al. 2004), thus there would not be sufficient external nutrition to initiate final gonad maturation. Similarly, Zhang et al. (2007) ascribed null egg production in the YSCWM during summer to food limitation, but unfortunately that study did not examine gonad development. On the other hand, we cannot exclude the possibility that immature females were experiencing dormancy, as did the immature females of Calanus glacialis in the Lurefjord (Niehoff \& Hirche 2005), though further measurements are still required to clarify this point.

It may be economical for females in the YSCWM to remain immature instead of wasting energy on offspring who will probably risk high mortality faced with the low temperature and poor food environment (Pu et al. 2004, Wang \& Zuo 2004, Zhang et al. 2007). It is probable that some of these females will survive and start maturation when the food conditions improve in early winter (Zhang 2003, S. Wang unpubl. data). Besides female immaturity, the main component of the population (C5s) remained dormant inside the YSCWM (Pu et al. 2004). These life history strategies may help Calanus sinicus reduce energy expenditures to maintain the population in the extreme environment during summer and autumn, waiting for improved conditions to recruit.

\section{Factors affecting reproduction}

The regression analyses imply that microzooplankton probably serves as an important nutritional source for the reproduction of Calanus sinicus (Tables $2 \& 3$ ). Although $C$. sinicus mainly feeds on phytoplankton, field studies suggest it may conduct omnivorous feeding, particularly when phytoplankton food is unfavorable (Zhang et al. 2006, Sun et al. 2007). During the 2 cruises, ciliate food accounted for up to $30 \%$ of the carbon intake in females, which tended to select ciliates rather than the more abundant phytoplankton taxa (Huo et al. 2008). Compared with other food items, ciliates may have higher nutritional value and therefore enhance reproduction (Kleppel et al. 1991, Kleppel 1993, Huo et al. 2008). To fully understand the roles of microzooplankton, other components, such as heterotrophic flagellates, should be incorporated into further studies, despite their far smaller contribution to the diet of C. sinicus than ciliates (Huo et al. 2008).
While several studies have reported the significance of phytoplankton in reproduction of Calanus sinicus (Uye \& Murase 1997, Zhang et al. 2005, Zhang et al. 2006), the relationship between EPR and chl a was not as strong as expected during this study (Table 2). Judging by particle size, the dominant phytoplankton species fell into the favorable food range for C. sinicus (Li et al. 2007, Huo et al. 2008), so chl a concentration could be considered as a proxy for potential phytoplankton food. However, the fit between fecundity and the current food supply might be affected by past feeding history and food quality (Jónasdóttir et al. 2002, Rey-Rassat et al. 2002), which, unfortunately, were not examined. Nevertheless, food items were the only factors included in the multiple regression models (Table 3), indicating their primary significance during reproduction.

The EPR of Calanus sinicus was independent of either absolute or relative oil storage amount (see 'Results'; Table 2). Besides, the lipid reserve generally could not initiate final gonad maturation and hence egg production of $C$. sinicus under limited food conditions; this agrees with the observations of Plourde \& Runge (1993) for the spring population of C. finmarchicus. These findings may indicate that reproduction of C. sinicus is dependent on external food rather than the lipid reserve, which likely serves as a nutrient buffer for metabolic needs. According to Lee et al. (2006), C. sinicus seems to belong to a zooplankton group requiring sufficient ingested food for successful reproduction. However, we observed a small proportion of mature females ( $5 \%$ ) at 1 station in the YSCWM in October (Table 1), implying that $C$. sinicus likely has certain flexibility of inner energy utilization, as reported in other species (Niehoff 2007).

The fecundity of Calanus sinicus was positively related to PL (Table 2), which might be mediated by the positive relationship between clutch size and PL as reported by Zhang et al. (2005). There were similar relationships in C. finmarchicus (Campbell \& Head 2000, Runge et al. 2006). It should be noted that the body size effect is indirect and weak, particularly in October: while autumn females developed similar body sizes among stations (Table 1), they displayed distinct fecundities ranging from 0 to 21.5 eggs female ${ }^{-1} \mathrm{~d}^{-1}$ (Fig. 5B).

We found the EPR of Calanus sinicus was independent of temperature (Table 2). Although previous laboratory research showed that higher temperature may increase EPR under saturated food conditions (Hirche et al. 1997), there is often no clear relationship between temperature and EPR during field studies, probably a result of the complex interactions among temperature and other environmental or intrinsic variables which may affect EPR (Campbell \& Head 2000, Gisla- 
son 2005, Runge et al. 2006). In this study, the temperature $\left(4.9\right.$ to $\left.24.0^{\circ} \mathrm{C}\right)$ was favorable for the reproduction of C. sinicus (Wang \& Zuo 2004); however, the effect of temperature might be masked by factors such as food and body size. Nevertheless, temperature may exert influences on reproduction of $C$. sinicus indirectly; for example, it has a negative effect on female body size (Uye 1988, this study), which can in turn influence the clutch size and the EPR (Zhang et al. 2005). Furthermore, temperature is a regulatory factor of the metabolic rate in C. sinicus (Li et al. 2004), thus it can alter the energy dispensation to reproduction and other physiological requirements.

External food plays a primary role on the gonad maturation and reproduction of Calanus sinicus, whereas inner lipid reserve may mainly serve metabolic needs. Body size has a positive effect on fecundity, probably via the clutch size. Rather than having a direct effect, temperature may exert influences indirectly on reproduction by regulating the metabolic rates and body size.

Acknowledgements. We thank the captain and crew of the RV 'Beidou' for their support during sampling. We are grateful to Prof. D. Huang for providing the temperature and salinity data. We also thank the anonymous referees for their valuable comments on an earlier version of the manuscript. This research was supported by special funds from Chinese Academy of Sciences (KZCX2-YW-213), National Natural Science Foundation of China $(40631008,40576070)$ and National Key Basic Research Program of China (2006CB400606).

\section{LITERATURE CITED}

Bunker AJ, Hirst AG (2004) Fecundity of marine planktonic copepods: global rates and patterns in relation to chlorophyll $a$, temperature and body weight. Mar Ecol Prog Ser 279:161-181

> Campbell RW, Head EJH (2000) Egg production rates of Calanus finmarchicus in the western North Atlantic: effects of gonad maturity, female size, chlorophyll concentration, and temperature. Can J Fish Aquat Sci 57:518-529

> Castellani C, Altunbas Y (2006) Factors controlling the temporal dynamics of egg production in the copepod Temora longicornis. Mar Ecol Prog Ser 308:143-153

Ceballos S, Álvarez-Marqués F (2006) Seasonal dynamics of reproductive parameters of the calanoid copepods Calanus helgolandicus and Calanoides carinatus in the Cantabrian Sea (SW Bay of Biscay). Prog Oceanogr 70:1-26

Ceballos S, Cabal JA, Álvarez-Marqués F (2004) Reproductive strategy of Calanoides carinatus and Calanus helgolandicus during a summer upwelling event off NW Spain. Mar Biol 145:739-750

Chen Q (1964) Study on the reproduction, sex ratio and body size of Calanus sinicus (in Chinese with English Abstract). Oceanol Limnol Sin 6:272-287

> Gislason A (2005) Seasonal and spatial variability in egg production and biomass of Calanus finmarchicus around Iceland. Mar Ecol Prog Ser 286:177-192

Halsband-Lenk C, Pierson JJ, Leising AW (2005) Reproduc- tion of Pseudocalanus newmani (Copepoda: Calanoida) is deleteriously affected by diatom blooms-a field study. Prog Oceanogr 67:332-348

Hirche HJ (1996) The reproductive biology of the marine copepod, Calanus finmarchicus - a review. Ophelia 44:111-128

Hirche HJ, Meyer U, Niehoff B (1997) Egg production of Calanus finmarchicus: effect of temperature, food and season. Mar Biol 127:609-620

Huo Y, Wang S, Sun S, Li C, Liu M (2008) Feeding and egg production of the planktonic copepod Calanus sinicus in spring and autumn in the Yellow Sea, China. J Plankton Res 30:723-734

Jónasdóttir SH, Gudfinnsson HG, Gislason A, Astthorsson OS (2002) Diet composition and quality for Calanus finmarchicus egg production and hatching success off southwest Iceland. Mar Biol 140:1195-1206

Jónasdóttir SH, Richardson K, Heath MR, Ingvarsdóttir A, Christoffersen A (2008) Spring production of Calanus finmarchicus at the Iceland-Scotland Ridge. Deep-Sea Res I Oceanogr Res Pap 55:471-489

Kleppel GS (1993) On the diets of calanoid copepods. Mar Ecol Prog Ser 99:183-195

Kleppel GS, Holliday DV, Pieper RE (1991) Trophic interactions between copepods and microplankton: a question about the role of diatoms. Limnol Oceanogr 36:172-178

Lee RF, Hagen W, Kattner G (2006) Lipid storage in marine zooplankton. Mar Ecol Prog Ser 307:273-306

Li C, Sun S, Wang R, Wang X (2004) Feeding and respiration rates of a planktonic copepod (Calanus sinicus) oversummering in Yellow Sea Cold Bottom Waters. Mar Biol 145: 149-157

> Li J, Sun S, Li C, Zhang Z, Tao Z (2006) Effects of single and mixed diatom diets on the reproduction of copepod Calanus sinicus. Acta Hydrochim Hydrobiol 34:117-125

Li C, Sun S, Wang R (2007) An experimental study on grazing selectivity of Calanus sinicus to natural food particles (in Chinese with English Abstract). Oceanol Limnol Sin 38: 529-535

Meng T (2003) Studies on the feeding of anchovy (Engraulis japonicus) at different life stages on zooplankton in the middle and southern waters of the Yellow Sea (in Chinese with English Abstract). Mar Fish Res 24:1-9

Miralto A, Barone G, Romano G, Poulet SA and others (1999) The insidious effect of diatoms on copepod reproduction. Nature 402:173-176

Niehoff B (2000) The effect of starvation on the reproductive potential of Calanus finmarchicus. ICES J Mar Sci 57: 1764-1772

Niehoff B (2007) Life history strategies in zooplankton communities: The significance of female gonad morphology and maturation types for the reproductive biology of marine calanoid copepods. Prog Oceanogr 74:1-47

Niehoff B, Hirche HJ (1996) Oogenesis and gonad maturation in the copepod Calanus finmarchicus and the prediction of egg production from preserved samples. Polar Biol 16: 601-612

> Niehoff B, Hirche HJ (2005) Reproduction of Calanus glacialis in the Lurefjord (western Norway): indication for temperature-induced female dormancy. Mar Ecol Prog Ser 285: 107-115

> Niehoff B, Runge JA (2003) A revised methodology for prediction of egg production of the marine planktonic copepod Calanus finmarchicus from preserved samples. J Plankton Res 25:1581-1587

Niehoff B, Klenke U, Hirche HJ, Irigoien X, Head R, Harris R (1999) A high frequency time series at Weathership $M$, Norwegian Sea, during the 1997 spring bloom: the repro- 
ductive biology of Calanus finmarchicus. Mar Ecol Prog Ser 176:81-92

Plourde S, Runge JA (1993) Reproduction of the planktonic copepod Calanus finmarchicus in the Lower St. Lawrence Estuary: relation to the cycle of phytoplankton production and evidence for a Calanus pump. Mar Ecol Prog Ser 102: 217-227

Pond D, Harris R, Head R, Harbour D (1996) Environmental and nutritional factors determining seasonal variability in the fecundity and egg viability of Calanus helgolandicus in coastal waters off Plymouth, UK. Mar Ecol Prog Ser 143: $45-63$

Poulet SA, Ianora A, Miralto A, Meijer L (1994) Do diatoms arrest embryonic development in copepods? Mar Ecol Prog Ser 111:79-86

> Pu X, Sun S, Yang B, Zhang G, Zhang F (2004) Life history strategies of Calanus sinicus in the southern Yellow Sea in summer. J Plankton Res 26:1059-1068

Rey C, Carlotti F, Tande K, Hygum BH (1999) Egg and faecal pellet production of Calanus finmarchicus females from controlled mesocosm and in situ populations: influence of age and feeding history. Mar Ecol Prog Ser 188:133-148

Rey-Rassat C, Irigoien X, Harris R, Head R, Carlotti F (2002) Egg production rates of Calanus helgolandicus females reared in the laboratory: variability due to present and past feeding conditions. Mar Ecol Prog Ser 238:139-151

Runge JA, Plourde S, Joly P, Niehoff B, Durbin E (2006) Characteristics of egg production of the planktonic copepod, Calanus finmarchicus, on Georges Bank: 1994-1999. Deep Sea Res II Top Stud Oceanogr 53:2618-2631

Su Y, Weng X (1994) Water masses in China Seas. In: Zhou D, Liang YB, Zeng CK (eds) Oceanology of China Seas, Vol 1. Kluwer Academic Publishers, London, p 3-26

Sun S (2005) Over-summering strategy of Calanus sinicus. GLOBEC Int Newsl 11:34

Sun J, Song S, Wang D, Xu Z (2007) Estimating Calanus sinicus grazing on phytoplankton and microzooplankton (in Chinese with English Abstract). Acta Ecol Sin 27:3302-3315

Editorial responsibility: William Peterson,

Newport, Oregon, USA
Svetlichny LS, Kideys AE, Hubareva ES, Besiktepe S, Isinibilir M (2006) Development and lipid storage in Calanus euxinus from the Black and Marmara seas: Variabilities due to habitat conditions. J Mar Syst 59:52-62

> Uye SI (1988) Temperature-dependent development and growth of Calanus sinicus (Copepoda: Calanoida) in the laboratory. Hydrobiologia 167-168:285-293

Uye SI, Murase A (1997) Relationship of egg production rates of the planktonic copepod Calanus sinicus to phytoplankton availability in the Inland Sea of Japan. Plankton Biol Ecol 44:3-11

Wang R, Zuo T (2004) The Yellow Sea Warm Current and the Yellow Sea Cold Bottom Water, their impact on the distribution of zooplankton in the Southern Yellow Sea. J Korean Soc Oceanogr 39:1-13

> Wang R, Zuo T, Wang K (2003) The Yellow Sea Cold Bottom Water-an oversummering site for Calanus sinicus (Copepoda, Crustacea). J Plankton Res 25:169-183

Weng X, Wang C (1982) Determining the boundary and range of temperature and salinity of Yellow Sea Cold Water Mass (in Chinese with English Abstract). In: Hydrometeorology. Chinese Society of Oceanology and Limnology Science, Beijing, p 61-70

Zhang G (2003) Reproductive strategy of Calanus sinicus in the southern Yellow Sea (in Chinese with English Abstract). PhD thesis, Institute of oceanology, Chinese Academy of Sciences, Qingdao

Zhang G, Sun S, Zhang F (2005) Seasonal variation of reproduction rates and body size of Calanus sinicus in the southern Yellow Sea, China. J Plankton Res 27:135-143

Zhang G, Li C, Sun S, Zhang H, Sun J, Ning X (2006) Feeding habits of Calanus sinicus (Crustacea: Copepoda) during spring and autumn in the Bohai Sea studied with the herbivore index. Sci Mar 70:381-388

Zhang G, Sun S, Yang B (2007) Summer reproduction of the planktonic copepod Calanus sinicus in the Yellow Sea: influences of high surface temperature and cold bottom water. J Plankton Res 29:179-186

Submitted: March 4, 2008; Accepted: December 19, 2008 Proofs received from author(s): March 15, 2009 